\title{
MicroRNA-374b inhibits liver cancer progression via down regulating programmed cell death-1 expression on cytokine-induced killer cells
}

\author{
FEN HUANG ${ }^{1}$, BO WANG ${ }^{2}$, JIANGZHENG ZENG ${ }^{1}$, SHENGGANG SANG $^{3}$, JUNHUA LEI $^{1}$ and YANDA LU ${ }^{1}$ \\ ${ }^{1}$ Department of Medical Oncology, The First Affiliated Hospital of Hainan Medical University, Haikou, Hainan 570102; \\ ${ }^{2}$ Department of Emergency, Hainan General Hospital, Haikou, Hainan 570311; ${ }^{3}$ Department of Clinical Laboratory, \\ The First Affiliated Hospital of Hainan Medical University, Haikou, Hainan 570102, P.R. China
}

Received June 13, 2017; Accepted November 29, 2017

DOI: 10.3892/ol.2018.7951

\begin{abstract}
Programmed cell death-1 (PD-1) is an oncogene associated with suppressing proliferation and cytokine production of $\mathrm{T}$ cells in the progression of liver cancer. microRNAs (miRs) regulate gene expression via specific binding to the target 3'untranslated region of mRNA. In the present study, miR-374b was indicated to interact with PD-1 and affect the tumor-targeting capacity of cytokine-induced killer (CIK) cells. miR-374b inhibitor significantly increased PD-1 expression in CIK cells. A synthetic small interfering (si)RNA targeting PD-1 was employed to silence the expression level of PD-1 in CIK cells. Then, the antitumor effect of siPD-1 in CIK cells was investigated. In vitro study demonstrated that IFN- $\gamma$ secretion and the concentration of lactate dehydrogenase were significantly increased in the PD-1 knockdown group; however, the viability of HepG2 cells in the PD-1 knockdown group had significantly decreased, compared with the HepG2 cells in the negative control group. In vivo study indicated that mice inoculated with HepG2 cells and CIK cells with PD-1 knocked down had a significantly smaller tumor volume, compared with the control group. To conclude, human CIK cells transfected with siPD-1 can target liver cancer cells and enhance immunotherapy efficacy, and therefore they have potential in the immunotherapy of liver cancer.
\end{abstract}

\section{Introduction}

Liver cancer is one of the most common malignant diseases globally (1). Between 2012 and 2017, numerous therapeutics of liver cancer have indicated potential in clinical trials, particularly

Correspondence to: Dr Yanda Lu, Department of Medical Oncology, The First Affiliated Hospital of Hainan Medical University, 31 Longhua Road, Haikou, Hainan 570102, P.R. China E-mail: luyandajx@sina.com.cn

Key words: liver cancer, microRNA-374b, cytokine-induced killer, programmed cell death-1 immunotherapies (2). Cytokine-induced killer (CIK) cells, which are the major histocompatibility complex-unrestricted cytotoxic lymphocytes generated with tumor necrosis factor- $\alpha$ (TNF- $\alpha$ ), interferon- $\gamma$ (IFN- $\gamma$ ), interleukin (IL)-2 and IL-12, serve an important role in immunotherapy (3). CIK cell-based immunotherapy has been indicated to be effective in the majority of tumors types, and is currently studied in clinical trialsfrequently $(4,5)$.

Programmed cell death-1 (PD-1) is a prominent regulator of T-cell function, and is expressed on $\mathrm{T}$ cells following chronic antigenic stimulation (6,7). Up regulation of PD-1 was identified to be associated with the suppression of T-cell function via mediating $\mathrm{T}$ cell apoptosis; however, down regulation of PD-1 was revealed to have the ability to reverse immune dysfunction (8-14). Clinical studies targeting the PD-1-PD-L1 axis have demonstrated effectiveness in a number of cancer types (15-17). Engagement of PD-1 in T cells with its ligand PD-L1 in tumor cells down regulates antitumor T-cell responses, and allows tumors to escape these responses $(18,19)$.

MicroRNAs (miRNAs), a class of highly conserved long noncoding RNA, regulate gene expression negatively via targeting the $3^{\prime}$ untranslated region (3'UTR) or coding region of the mRNA; additionally, they participate in a number of biological processes, including cell proliferation, differentiation, apoptosis and tumorigenesis $(20,21)$. A previous study indicated that miRNAs are involved in regulation of the immune system and development of immune cells (22).

The microRNA database (miRBase, release 21, http://www. mirbase.org/cgi-bin/query.pl?terms $=$ miR-374) demonstrated that miR-374a and miR-374b may bind the 3'UTR region of PD-1 mRNA (miRSVR score $\leq 0.1$ ). Research has also indicated that miR-374a and miR-374b could be expressed in cluster of differentiation (CD) 4+T, CD8+T and natural killer (NK) cells $(23,24)$. In the present study, it was demonstrated that miR-374b binds to the 3'UTR of PD-1 by using Dual-Luciferase Reporter Assay. Therefore, miR-374b was selected as the research target. In recent years, studies have indicated that miR-374b affects the apoptosis ability of colorectal cancer cells $(25,26)$. miR-374b can accelerate cell proliferation and the production of aberrant glycosylated immunoglobulin (Ig) A1 in B cells (27), and it has the ability to participate in the 
development of human osteosarcoma cells (28). Additionally, miR-374b can negatively regulate $\mathrm{C} 2 \mathrm{C} 12$ myoblast differentiation via targeting Myf6 (29), and inhibit proliferation and promote apoptosis of T-cell lymphoblastic lymphoma (30). In addition, miR-374b is associated with cisplatin resistance in pancreatic cancer cells (31), andit is capable of accelerating invasion and metastasis of gastric cancer cells (32); however, the role of miR-374b in liver cancer remains unclear. Therefore, it is essential to explore miR-374b, which may become anovel promising therapeutic target for liver cancer.

In the present study, miR-374b was predicted to interact with PD-1 and was demonstrated to affect the tumor-targeting capacity of CIK cells. The result indicated that siPD-1 promoted the CIK secreting cytokine, but inhibited the viability of HepG2 cells. In vivo study indicated that siPD-1 decreased the tumor volume in liver cancer mouse models. In conclusion, human CIK cells transfected with siPD-1 can target liver cancer cells and enhance immunotherapy efficacy, and therefore have a potential in the immunotherapy of liver cancer.

\section{Materials and methods}

Cell lines and transfection. Liver cancer cell lines (HepG2, PLC and Huh7) were purchased from American Type Culture Collection (Manassas, VA, USA) and cultured in Dulbecco's modified Eagle's medium (DMEM; In vitro gen; Thermo Fisher Scientific, Inc., Waltham, MA, USA), and normal hepatocytes (L-02 cells) were cultured in RPMI-1640 medium (In vitro gen; Thermo Fisher Scientific, Inc.). Each medium contained 10\% fetal calf serum (FCS; Sigma-Aldrich; Merck KGaA, Darmstadt, Germany) and $1 \%$ penicillin-streptomycin $\mathrm{G}$ (In vitro gen; Thermo Fisher Scientific, Inc.). All cells were incubated at $37^{\circ} \mathrm{C}$ in a humidified atmosphere of $5 \% \mathrm{CO}_{2}$.

miR-374b mimic, negative control (NC), miR-374b inhibitor oligonucleotides and PD-1 siRNA were synthesized by Shanghai Gene Pharma, Co., Ltd. (Shanghai, China) and the sequences are as follows: miR-374b mimics, 5'-AUAUAA UACAACCUGCUAAGUG-3'; NC, 5'-UUCUCCGAACGU GUCACGUTT-3'; miR-374b inhibitor, 5'-CACUUAGCAGGU UGUAUUAUAU-3'; PD-1 siRNA, 5'-CCAGGAUGGUUC UUAGACUUU-3'.

In all experiments, the incubation was conducted at $37^{\circ} \mathrm{C}$ in a humidified atmosphere containing $5 \% \mathrm{CO}_{2}$. CIK cells were generated from peripheral blood mononuclear cells (PBMCs) of healthy volunteers. A total of $2 \times 10^{4}$ cells in the logarithmic phase were seeded into each well of a 6-well plate in $2 \mathrm{ml}$ of Opti-MEM I reduced serum medium (Life Technologies; Thermo Fisher Scientific, Inc., Waltham, MA, USA) and incubated over night at $37^{\circ} \mathrm{C}$ in a humidified atmosphere of $5 \% \mathrm{CO}_{2}$. The next day, cells were transfected with $50 \mu \mathrm{M}$ scramble siRNA (negative control, NC), $50 \mu \mathrm{M}$ PD-1 siRNAs, $50 \mathrm{nM}$ miR-374b mimic, $50 \mathrm{nM}$ negative control (NC) and $50 \mathrm{nM}$ miR-374b inhibitor oligonucleotides for 48 h using Lipofectamine ${ }^{\circledR} 2000$ reagent (In vitro gen; Thermo Fisher Scientific, Inc.) according to the manufacturer's protocol.

Preparation and identification of human CIK cells. Human PBMCs were obtained from healthy donors via Ficoll-Hypaque density centrifugation $\left(3,000 \mathrm{x}\right.$ g for $30 \mathrm{~min}$ at $\left.4^{\circ} \mathrm{C}\right)$, and then washed three times with PBS. Cells were resuspended in $5 \mathrm{ml}$ RPMI-1640 medium containing $1 \times 10^{6} \mathrm{U} / 1$ human IFN- $\gamma$ (R\&D Systems, Inc., Minneapolis, MN, USA; cat no., 285-IF) at a concentration of $\sim 3 \times 10^{6}$ cells $/ \mathrm{ml}$ and incubated overnight at $37^{\circ} \mathrm{C}$ in an atmosphere containing $5 \% \mathrm{CO}_{2}$. After 24 h, 1,000 units/ml IL-2 (Chiron Corporation, Emeryville, CA, USA), IL-1a (Chiron Corporation), $50 \mu \mathrm{g} / 1$ each of allophycocyanin-conjugated anti-CD3 (cat. no., 553066; BD Biosciences, Franklin Lakes, NJ, USA) and anti-CD28 (cat no., 14-02281-86, eBioscience; Thermo Fisher Scientific, Inc.) monoclonal antibodies (mAbs) were added. Fresh medium and fresh IL-2 (cat no., 575406) were added every 2 days and the cells were harvested on days 1,7, 14 and 21 and assessed using FACS (FACSCalibur ${ }^{\mathrm{TM}}$; BD Biosciences, Franklin Lakes, NJ, USA) with fluorescein isothiocyanate-conjugated anti-CD3 (cat no., 555274; BD Biosciences) and phycoerythrin-CD56 (cat no., 561903; BD Bioscience) using Flow Jo software (version 8.7.1; Flow Jo LLC, Ashland). The protocol for the present study was approved by The Ethical Review Committee of The First Affiliated Hospital of Hainan Medical University (Hainan Province, China). Informed consent was obtained from each person.

Luciferase reporter assay. The database Target Scan (http://www.targetscan.org) was used to predict potential targets for miR-374b. DNA fragments of the PD-1 3'UTR containing the putative miR-374b binding site or mutated (Mut) miR-374b binding site were amplified bypolymerase chain reaction (PCR) using 2x Taq PCR Master Mix (Tiangen Biotech Co., Ltd., Beijing, China) from CIK cell genomic DNA. The thermocycling conditions were as follows: $95^{\circ} \mathrm{C}$ for 5 mins, then 35 cycles of $95^{\circ} \mathrm{C}$ for $30 \mathrm{secs}, 57^{\circ} \mathrm{C}$ for $30 \mathrm{secs}, 72^{\circ} \mathrm{C}$ for $1 \mathrm{~min}$, followed by an extension at $72^{\circ} \mathrm{C}$ for $10 \mathrm{~min}$. The primers were as follows: PD-1-XhoI 5'-CCGCTCGAGCAGTAAGCGGGCAGGC-3' (forward), PD-1-NotI5'-ATTTGCGGCCGCTCCTTAGCA TGCTCTCATATTT-3' (reverse); PD-1-MUT 5'-CCTTCC CTGTGGTTCGCACTGGTTATAATTATAA-3' (forward), PD-1-MUT 5'-TTATAATTATAACCAGTGCGAACCACA GGGAAGG-3' (reverse). The DNA products were then inserted into the Pme I/Spe I sites of the firefly luciferase coding region of the pMIR-report vector (Thermo Fisher Scientific, Inc.). The plasmids were termed as wild-type (pMIR-report-PD-1-WT) and Mut (pMIR-report-PD-1-Mut) sequences. The mutation of UAAUAU to AUUAUA was introduced into the potential miR-374b binding sites. A total of $8 \times 10^{4}$ cells) were cultured in each well of a 96-well plate, and co-transfected with miR-374b mimic and NC, and WT or Mut 3'-UTR of PD-1using Lipofectamine 2000 reagent (In vitro gen; Thermo Fisher Scientific, Inc.) according to the manufacturer's protocolat $37^{\circ} \mathrm{C}$ in an incubator with $5 \% \mathrm{CO}_{2}$ for $48 \mathrm{~h}$. The luciferase activities were detected by Dual-Luciferase Reporter Assay ki (Promega Corporation, Madison, WI, USA; cat. no., E1910). Cells were collected, washed using PBS and lysed in Passive Lysis Buffer (Promega Corporation) at $48 \mathrm{~h}$ following transfection. The Dual-Luciferase Reporter Assay System (Promega Corporation) was used to analyze the data the Renilla luciferase reporter was used as the internal control. Data are presented as the means \pm standard deviation (SD) of three independent experiments. 
$R N A$ extraction and reverse transcription-quantitative $P C R$ $(R T-q P C R)$. Total RNA was isolated using TRIzol ${ }^{\circledR}$ (In vitro gen; Thermo Fisher Scientific, Inc.), accordingly to the manufacturer's instructions, and reversely transcribed to cDNA via RT-PCR using a mi Script II RT Kit (Qiagen GmbH, Hilden, Germany). The mRNA expression levels were detected using the SYBR ${ }^{\circledR}$ Green PCR Master Mix kit (Clontech Laboratories, Inc., Mountain view, CA, USA). The reaction system was performed in a volume of $20 \mu \mathrm{l}$, and the thermo cycling conditions were as follows: $95^{\circ} \mathrm{C}$ for $10 \mathrm{~min}$, then 40 cycles of $95^{\circ} \mathrm{C}$ for $10 \mathrm{sec}, 60^{\circ} \mathrm{C}$ for $2 \mathrm{~min}, 72^{\circ} \mathrm{C}$ for $2 \mathrm{~min}$, followed by an extension at $72^{\circ} \mathrm{C}$ for $10 \mathrm{mins}$. The target genes and controls were analyzed via RT-qPCR and the reactions were performed on the ABI 7500 system (Applied Biosystems; Thermo Fisher Scientific, Inc.) with primers specific for target genes: PD-1, forward: 5'-ATGACAGCG GCACCTACCT-3', reverse: 5'-CCTATTGTCCCTCGTGCG-3'; miR-374b-5p, forward: 5'-ACACTCCAGCTGGGATATAAT ACAACCTGCTA-3', reverse: 5'-CTCAACTGGTGTCGT GGAGTCGGCAATTCAGTTGAGCACTTAGC-3'; PD-L1, forward: 5'-CCATCAAGTCCTGAGTGGTAAG-3', reverse: 5'-TTGTTGTGTTGATTCTCAGTGTG-3'; GAPDH, forward: 5'-TGTTCGTCATGGGTGTGAAC-3', reverse: 5'-ATGGCA TGGACTGTGGTCAT-3'; U6, forward: 5'-CTCGCTTCGGCA GCACA-3', reverse: 5'-AACGCTTCACGAATTTGCGT-3'. The data were analyzed using $2^{-\Delta \Delta \mathrm{Cq}}(33)$. The relative $\mathrm{mRNA} / \mathrm{miRNA}$ expression levels were normalized to GAPDH/U6. All data were presented as the mean \pm SD of three independent experiments.

Western blot analysis. Cell lysates were prepared in RIPA buffer (Beyotime Institute of Biotechnology, Shanghai, China) via incubation for $20 \mathrm{~min}$ at $4^{\circ} \mathrm{C}$. The protein concentrations were determined using a BCA Protein Assay kit (Thermo Fisher Scientific, Inc.). Equal amounts of total proteins $(30 \mu \mathrm{g})$ were separated using $10 \%$ SDS-PAGE gels based on the molecular weight of the objective proteins and transferred onto a polyvinylidene difluoride membranes (Perkin Elmer, Inc., Waltham, MA, USA). The PVDF membranes were blocked in 5\% skim milk (BD Biosciences, Franklin Lakes, NJ, USA) for $2 \mathrm{~h}$ at room temperature. Following this, the cells were incubated with anti-GAPDH (dilution, 1:1,000; Santa Cruz Biotechnology, Inc., Dallas, TX, USA; cat. no. sc-365062) and anti-PD-1 antibody (dilution, 1:1,000; Abcam, Cambridge, UK; cat no. ab52587) at $4^{\circ} \mathrm{C}$ overnight. The blots were subsequently incubated with horseradish peroxidase (HRP)-conjugated secondary antibodies (goat anti-mouse; dilution, 1:2,000; cat no., SC-2005, and goat anti-rabbit; dilution, 1:2,000, cat no., SC-2004) for $1 \mathrm{~h}$ at room temperature. Finally, the proteins were detected using an ECL detection kit (EMD Millipore, Billerica, MA, USA).

PD-1 expression on liver cancer cells via flow cytometry. The liver cancer cell lines were cultured in DMEM (In vitro gen; Thermo Fisher Scientific, Inc., Waltham, MA, USA) with $10 \%$ FBS and the normal hepatocytes were cultured in RPMI-1640 medium (In vitro gen; Thermo Fisher Scientific, Inc.) with $10 \% \mathrm{FBS}$ at $37^{\circ} \mathrm{C}$ in a humidified atmosphere of $5 \% \mathrm{CO} 2$. Liver cancer cell lines were centrifuged separately $\left(100 \mathrm{x} \mathrm{g}\right.$ for $5 \mathrm{mins}$ at $\left.4^{\circ} \mathrm{C}\right)$ and the concentration of cells was adjusted to $1 \times 10^{6} \mathrm{cell} / \mathrm{ml}$ by using phosphate-buffered saline (PBS, cat. No. D-1408). Then, $1 \mathrm{ml}$ cell suspension was obtained and anti-human CD279 (PD-1) phycoerythrin (PE) monoclonal antibody (dilution, 1:50; cat no., 12-9985-82; eBioscience; Thermo Fisher Scientific, Inc.) was added, and cultured at $4^{\circ} \mathrm{C}$ for $30 \mathrm{~min}$. Cells were resuspended in $500 \mu \mathrm{l}$ PBS for flow cytometry (FACSCalibur Flow Cytometer; BD Biosciences) and analyzed with Flow Jo (version 4.5.4; Flow Jo LLC, Ashland). Mouse IgG1 K Iso type Control PE antibody (dilution, 1:50; cat. no. 12-4301; eBioscience; Thermo Fisher Scientific, Inc.) was used as a NC. All data are performed as the mean $\pm \mathrm{SD}$ of three independent experiments.

Cytokine secretion assays. $3 \times 10^{5}$ cells were seeded into a 6-well microplate (cat no., 353046BD; Biosciences,) and incubated at $37^{\circ} \mathrm{C}$ overnight. RPMI-1640 medium was added without FCS, and the secretion of IFN- $\gamma$ was measure dusing an enzyme-linked immunosorbent assay (ELISA) kit (cat no., DY459; R\&D Systems, Inc.) after incubation for $72 \mathrm{~h}$ at $37^{\circ} \mathrm{C}$ according to the manufacturer's instructions. All data are presented as the mean \pm SD of 3 independent experiments.

Cell counting kit-8 (CCK-8) assay. Cell viability was determined using a cell counting kit-8 (CCK-8; cat no., CK04-11; Dojindo Molecular Technologies, Inc., Rockville, MD, USA). Effect cells (CIK cells) and target cells (HepG2 cells) with a 20:1 ratio of effect: target $(\mathrm{E} / \mathrm{T})$ cells were seeded at a density of $6 \times 10^{3}$ in a 96-well plate (Corning Life Sciences, Tewksbury, MA, USA) for $24 \mathrm{~h}$ at $37^{\circ} \mathrm{C}$. Following this, the cells were washed using PBS once. Then, $100 \mu \mathrm{l}$ RPMI-1640 medium and $10 \mu \mathrm{l} \mathrm{CCK}-8$ was added to each well. Following $2 \mathrm{~h}$ at $37^{\circ} \mathrm{C}$, the 96-well plate was measured at $450 \mathrm{~nm}$ using a standard micro plate reader $\left(\right.$ Scientific $^{\mathrm{TM}}$ Multiskan $^{\mathrm{TM}}$ MK3; Thermo Fisher Scientific, Inc.). The cell viability was calculated according to the formula: Cell viability $=[$ optical density (OD) of the experimental sample/OD of the control group] $\mathrm{x} 100 \%$. HepG2 cells treated with an equivalent volume of PBS served as the negative control group, and the experiment was repeated 3 times.

Cytotoxicity assay. A lactate dehydrogenase (LDH) release assay was used to determine the cytotoxicity of the immune cells. The ratio of E/T cells was 20:1. Target cells and effect cells were added to a 96-well culture plate with incomplete medium (DMEM/10\% FBS/100 U/ml Penicillin-Streptomycin) for triplicate wells and incubated for $24 \mathrm{~h}$ in a humidified atmosphere containing $5 \% \mathrm{CO}_{2}$ at $37^{\circ} \mathrm{C}$. Following centrifugation of the suspension at $1,700 \mathrm{x} \mathrm{g}$ for $4 \mathrm{~min}$ at $4^{\circ} \mathrm{C}, 50 \mu \mathrm{l}$ was removed and mixed with $50 \mu 1 \mathrm{LDH}$ substrate solution (cat. no., L2402, Sigma-Aldrich; Merck KGaA) and then incubated for $30 \mathrm{~min}$ at room temperature in the dark. Finally, $50 \mu \mathrm{l}$ stop solution (50\% dimethyl form amide and $20 \%$ sodium dodecyl sulfate; $\mathrm{pH}$ 4.7) was added and the concentration of LDH in each well was measured using an automatic ELISA reader (ELISA reader; ASYS Hitech, GmbH, Austria). All data are performed as the mean $\pm \mathrm{SD}$ of three independent experiments.

Animals. A total of 24 female nude mice (6-8 weeks-old and weighing 22-24 g) were purchased from Laboratory Animal Center of Hainan Medical University. All mice were maintained in the Laboratory Animal Center of Hainan Medical 
University at a controlled temperature $\left(25-28^{\circ} \mathrm{C}\right)$ and a humidity within 50-60\%, under a 12/12 h light/dark cycle, with ad libitum access to sterile food and water. All the experiments were approved and performed according to the Animal Ethics Committee of Hainan Medical University.

Winn assay. A Winn assay was conducted to examine the tumor growth-suppressing effect of CIK cells in mice ( $\mathrm{n}=6$ ). The E/T ratio was 10:1. CIK, miR-374b inhibitor, PD-1 siRNA and HepG2 (CIK+Inhibitor+siRNA+HepG2) cells $\left(1 \times 10^{6}\right)$ or $\mathrm{CIK}+$ Inhibitor+NC+HepG2 (control) cells $\left(1 \times 10^{6}\right)$ were incubated for $12 \mathrm{~h}$ at $37^{\circ} \mathrm{C}$, adjusted to a sugar concentration of $1.5 \mathrm{mg} / \mathrm{ml}$, and then were subcutaneously injected into the leg of nude mice. The volume of the tumors was measured on 7 , 14, 21 and 28 days, respectively. Following the completion of the administration, the mice were sacrificed at 28 days, with the maximum tumor size measuring $360 \mathrm{~mm}^{2}$.

Adoptive transfer assay. To study the immunotherapy effect of CIK on liver cancer, the mice $(\mathrm{n}=12)$ were randomly divided into two groups according to the different treatments received: i) Inhibitor+NC+HepG2; and ii) Inhibitor+siRNA+HepG2. The treated HepG2 (1.5x107 cells/injection) cells were subcutaneously infected into the leg of nude miceonce. A week later, CIK cells $\left(1.0 \times 10^{7}\right)$ were intravenously injected in the mice via their tail veinsonce a week. The volume of the tumors was measured on days 7, 14, 21 and 28. Following the completion of the administration, the mice were sacrificed at 28 days, with the maximum tumor size measuring $422 \mathrm{~mm}^{2}$.

Statistical analysis. Data are expressed as mean \pm SD. One-way analysis of variance and Dunnett's post-hoc test were calculated using the SPSS software package version 11.5 (SPSS, Inc., Chicago, IL, USA). P $\leq 0.05$ was considered to indicate statistically significant difference.

\section{Results}

Preparing CIK cell bi-specific antibodies against CD3 and CD56. Peripheral blood was collected from healthy donors. On days 1,7, 14 and 21, mouse anti-human CD3 and CD56 mAbs were used to analyze the phenotypes of the cells measured via flow cytometry. The results in Fig. 1 depicted that following incubation with multiple cytokines for 1,7, 14 and 21 days, the percentage of $\mathrm{CD} 3+$ cells and $\mathrm{CD} 3+\mathrm{CD} 56+$ cells significantly increased $(\mathrm{P}<0.001)$, whilst the percentage of $\mathrm{CD} 4+$ cells did not change significantly. In combination, the data indicated that the CIK cells were mainly composed of T cells and NK $\mathrm{T}$ cells.

Predicting that miR-374b binds to the 3'UTR of PD-1 mRNA. To experimentally confirm that PD-1 is an authentic target of miR-374b in CIK cells, the PD-1-WT and PD-1-Mut luciferase reporter vectors were transfected into CIK cells in combination with $\mathrm{NC}$ or miR-374b mimic. Following $48 \mathrm{~h}$ of transfection, the results demonstrated that the luciferase activity in the PD-1-WT with miR-374b mimic group was significantly reduced, compared with the other three groups $(\mathrm{P}<0.01 ;$ Fig. $2 \mathrm{~A})$. The aforementioned data demonstrated that $\mathrm{PD}-1$ is a genuine target of miR-374b.
Effect of miR-374b on PD-1 expression. Due to the level of miR-374b being increased in CIK cell lines, its role in CIK cells was investigated. A miR-374b mimic was used to amplify the expression of miR-374b and a synthetic inhibitor specific for miR-374b was employed to suppress the expression of miR-374b in CIK cell lines. The efficiency of this miR-374b mimic or inhibitor was confirmed using qPCR. The relative miR-374b RNA expression was notably increased in the miR-374b mimic transfected group $(\mathrm{P}<0.01$, compared with the NC), however significantly decreased in miR-374b inhibitor transfected group $(\mathrm{P}<0.01$, compared with the NC and miR-374b mimic groups; Fig. 2B). The PD-1 expression levels in the NC, miR-374b mimic and miR-374b inhibitor groups were confirmed using qPCR and western blot analysis. The results demonstrated that PD-1 expression levels in the miR-374b mimic group were significantly reduced $(\mathrm{P}<0.05$, compared with $\mathrm{NC}$ group), however, significantly increased in miR-374b inhibitor group. $(\mathrm{P}<0.01$, compared with the $\mathrm{NC}$ and miR-374b mimic groups; Fig. 2C and D).

Effect of siPD-1 on CIK cells. The PD-1 expression levels were confirmed using qPCR and western blot analysis. The relative PD-1 mRNA expression levels and protein expression levels were significantly decreased in the siPD-1 group, compared with the NC group $(\mathrm{P}<0.01$; Fig. $2 \mathrm{E}$ and $\mathrm{F})$.

Selecting the high PD-1 expression liver cancer cell line. Compared with the L-02 cells group, PD-1 expression was significantly increased in HepG2 group $(\mathrm{P}<0.01)$, as demonstrated via flow cytometry, RT-PCR and western blot analysis. Consequently, HepG2 cells were selected for the following transfecting experiments (Fig. 3).

Effect of PD-1 on IFN- $\gamma$ production of CIK cells. A synthetic siRNA targeting PD-1 was employed to silence the expression level of PD-1 in CIK cells. The secretion of IFN- $\gamma$ was measured using an ELISA. The result demonstrated that IFN- $\gamma$ secretion was significantly increased in the CIK+Inhibitor+siRNA group, compared with the $\mathrm{CIK}+$ Inhibitor+NC group $(\mathrm{P}<0.01$; Fig. 4A).

Effects of siPD-1 on cytotoxicity of CIK cells. A LDH release assay was used to determine the cytotoxicity of the immune cells. the concentration of LDH in the $\mathrm{CIK}+$ Inhibitor+siRNA+HepG2 group was significantly increased, compared with the $\mathrm{CIK}+$ Inhibitor $+\mathrm{NC}+\mathrm{HepG} 2$ group $(\mathrm{P}<0.01$; Fig. 4B).

Effects of siPD-1 transfected CIK on HepG2 cell viability. Following this, PD-1 siRNA was designed and transfected into CIK cells to knockdown the endogenous expression of PD-1. A CCK-8 assay was performed to visualize the proliferation of the HepG2 cells. the viability of HepG2 cells in the CIK+Inhibitor+siRNA+HepG2 group was significantly decreased, compared with the $\mathrm{CIK}+$ Inhibitor $+\mathrm{NC}+\mathrm{HepG} 2$ group ( $\mathrm{P}<0.01$; Fig. 4C).

Antitumor effect of siPD-1 transfected CIK cells in nude mice. Winn assay and adoptive transfer assay were used to examine the antitumor effect of siPD-1 transfected CIK cells in nude 
CD3+
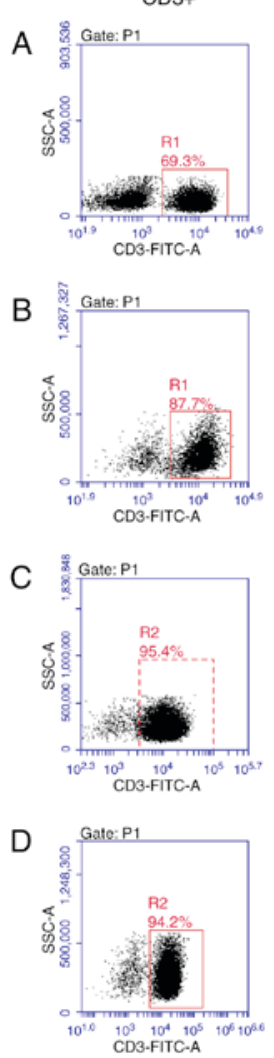

$\mathrm{CD} 3+\mathrm{CD} 4+$
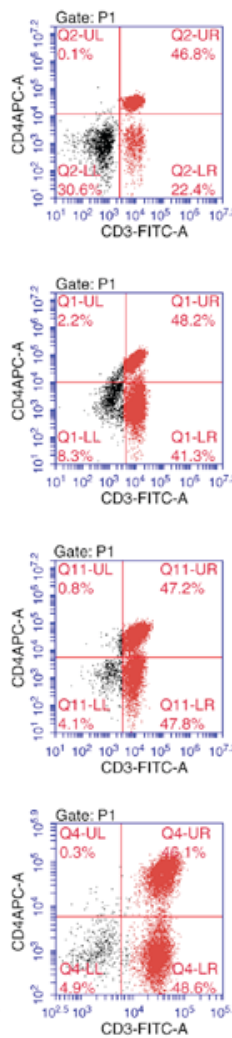

$\mathrm{CD} 3+\mathrm{CD} 8+$
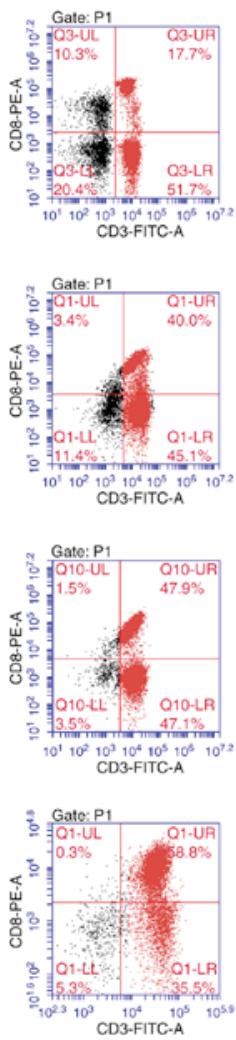

$\mathrm{CD} 3+\mathrm{CD} 56+$
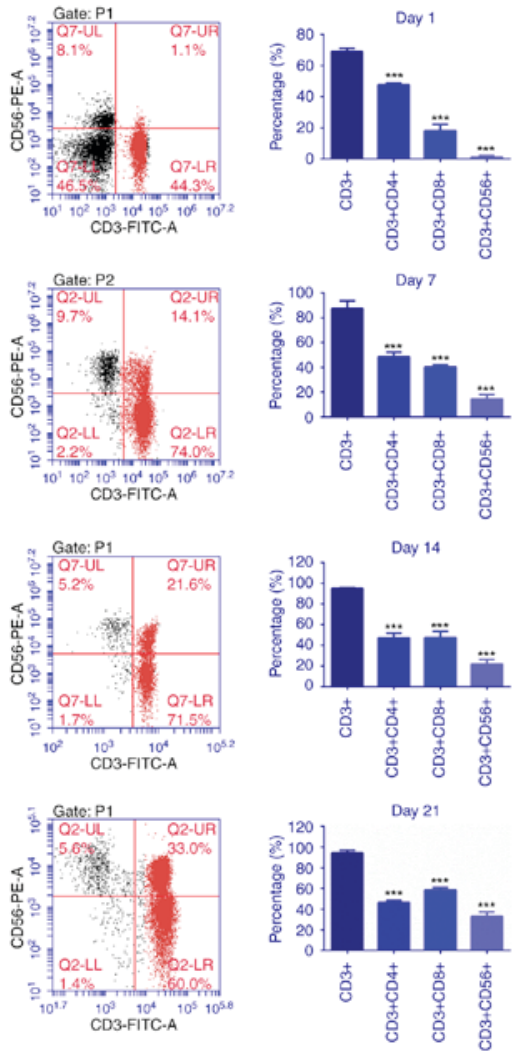

Figure 1. Characterization of cytokine-induced killer cells. Peripheral blood was collected from healthy donors and patients, and peripheral blood mononuclear cells were isolated and cultured for 21 days as described. On days (A) 1, (B) 7, (C) 14 and (D) 21, mouse anti-human CD3, CD4, CD8 and CD56 monoclonal antibodies were used to stain the cells, and the phenotype of the cells was measured via flow cytometry. Representative flow cytometry analyses are depicted. Following induction with multiple cytokines, the percentages of CD3+ and CD3+CD56+ cells significantly increased. CD, cluster of differentiation. ${ }^{* * * *} \mathrm{P}<0.001$ vs. CD3+ group.
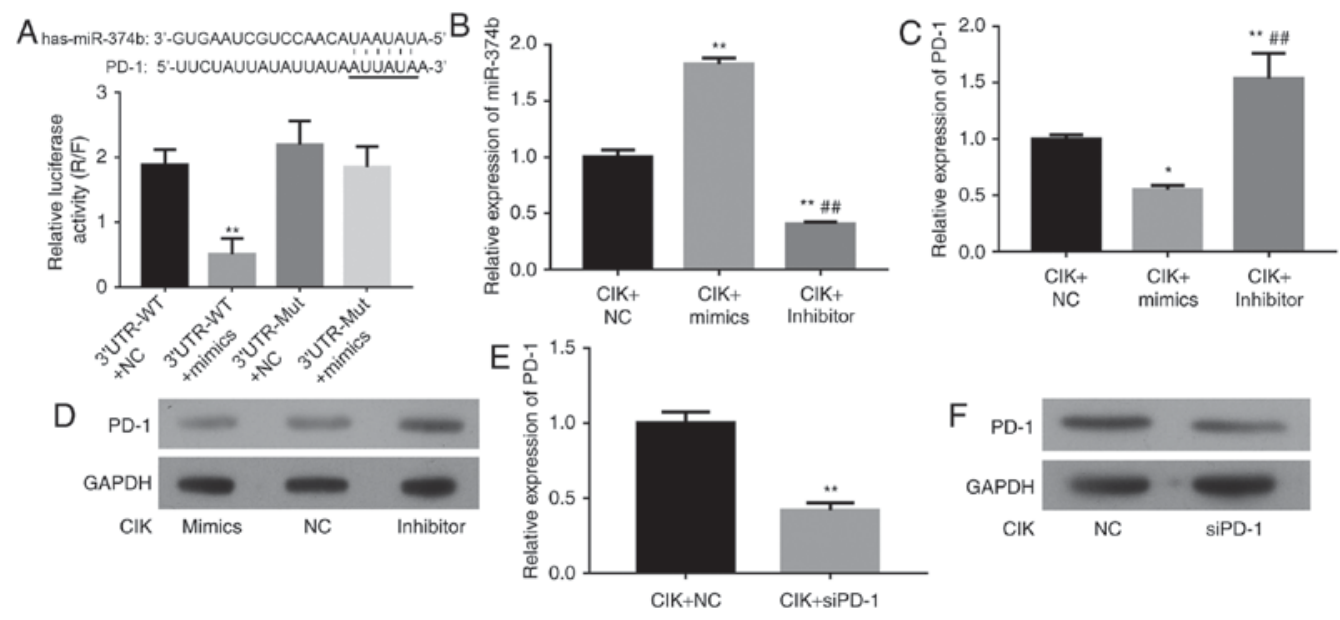

Figure 2. The targeting association between miR-374b and PD-1. (A) The target gene was predicted using the Target Scan database. Following $48 \mathrm{~h}$ of transfection, the luciferase activities of the four groups were detected by dual-Luciferase reporter gene system. The results indicated that the luciferase activity of PD-1-WT with miR-374b mimic group was significantly reduced, compared with the other three groups $\left({ }^{* *} \mathrm{P}<0.01\right)$. (B) CIK cells were transfected with NC, miR-374b mimic or miR-374b inhibitor. The efficiency of this miR-374b mimic or inhibitor was confirmed via qPCR assay. (C) Relative PD-1 mRNA expression level in transfected CIK cells was confirmed via qPCR ("P<0.05 vs. NC group; ${ }^{* *} \mathrm{P}<0.01$, compared with $\mathrm{NC}$ group; ${ }^{* \#} \mathrm{P}<0.01$, compared with miR-374b mimic group). (D) PD-1 protein expression levels were confirmed via western blot analysis. GAPDH was used as a reference. (E and F) CIK cells were transfected with NC or siPD-1. The efficiency of siPD-1 was confirmed via qPCR and western blot analysis ( ${ }^{* *} \mathrm{P}<0.01$ vs. NC group). WT, wild type; Mut, mutated; UTR, untranslated region; CIK, cytokine-induced killer; NC, negative control; siPD-1, small interfering programmed cell death-1; qPCR, quantitative polymerase chain reaction; miR, microRNA; Inhibitor, miR-374b inhibitor.

mice. The result demonstrated that the volume of the tumors in CIK+Inhibitor+siRNA+HepG2 group was notably reduced, compared with the CIK+Inhibitor+NC+HepG2 group $(\mathrm{P}<0.05$ and $\mathrm{P}<0.01$ at different time points; Fig. $4 \mathrm{D}$ and $\mathrm{E}$ ). 

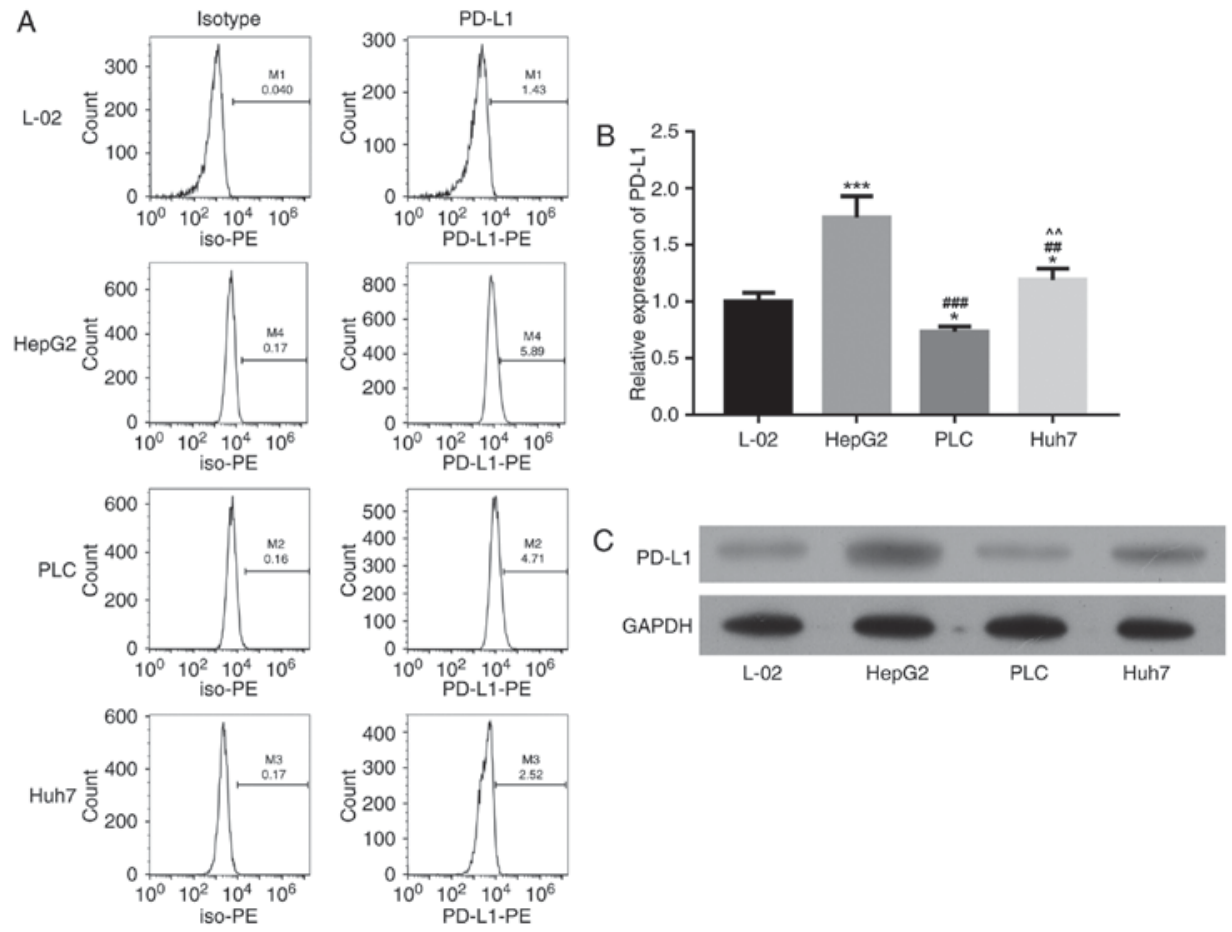

Figure 3. Selecting the high PD-L1 expression liver cancer cell line. PD-L1 expression in L-02, HepG2, PLC and Huh7 cells were assessed via (A) flow cytometry, (B) reverse transcription-polymerase chain reaction and $(\mathrm{C})$ western blot analysis $\left({ }^{*} \mathrm{P}<0.05,{ }^{* * * *} \mathrm{P}<0.001\right.$ vs. L-02 group; ${ }^{\# \#} \mathrm{P}<0.01,{ }^{\# \# \#} \mathrm{P}<0.001$ vs. HepG2 group; ${ }^{\wedge} \mathrm{P}<0.01$ vs. PLC group). PD-L1, programmed cell death-1 ligand. Iso-PE, isotype control; PE, phycoerythrin.
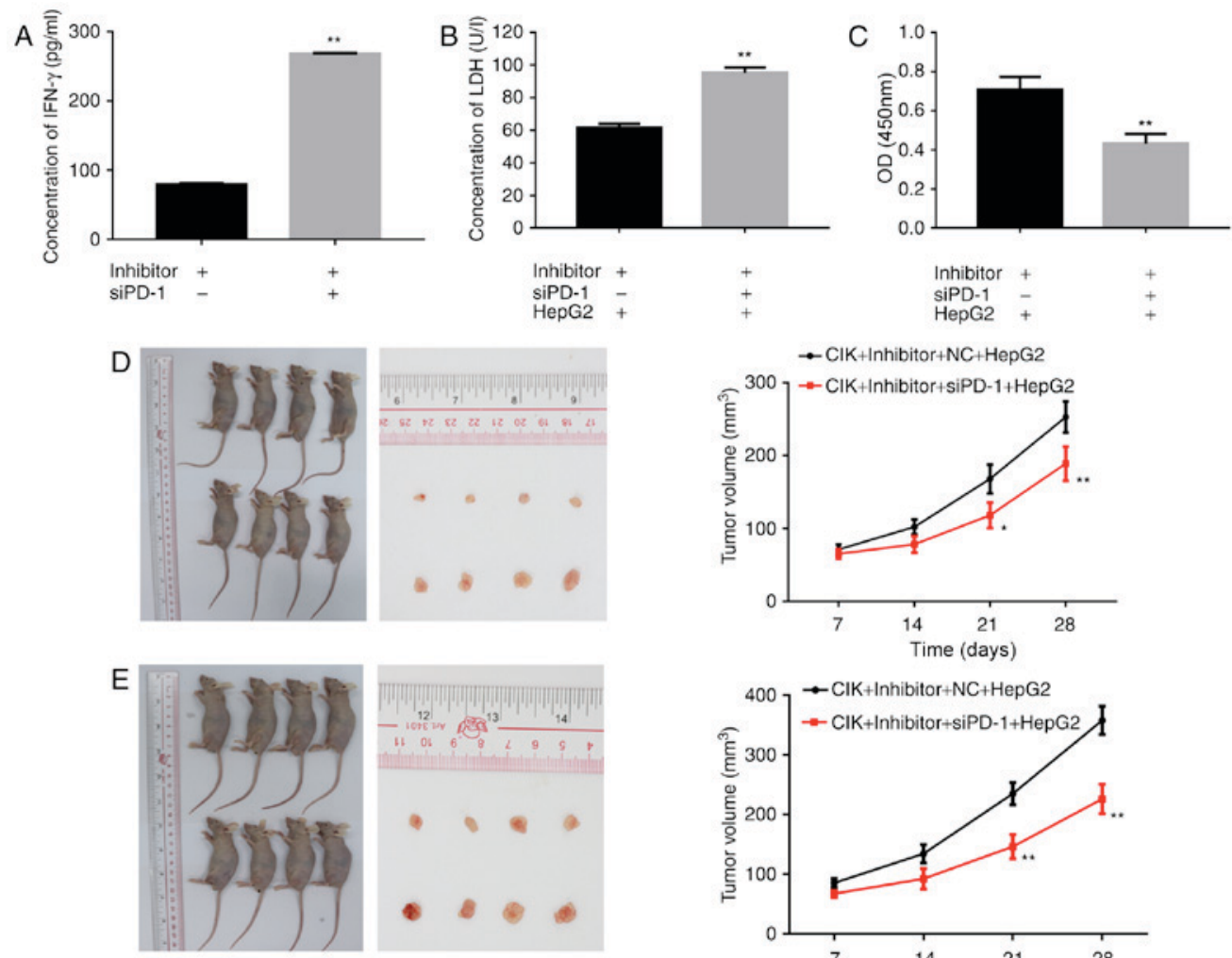

Figure 4. Effect of PD-1 on IFN- $\gamma$ production, cell viability, cytotoxicity and antitumor effect in CIK cells in vitro and in vivo. A synthetic siRNA targeting PD-1 was employed to silence the expression level of PD-1 in CIK cells. (A) An ELISA was used to measure the expression of IFN- $\gamma$ in CIK cells. The bands were quantified ("* $\mathrm{P}<0.01$ vs. CIK+Inhibitor+NC group). (B) ALDH release assay was used to determine the cytotoxicity of the CIK on HepG2 cells ("* $<<0.01$ vs. $\mathrm{CIK}+$ Inhibitor+NC+HepG2 group). (C) The Cell Counting Kit-8 assay was performed to visualize the proliferation of HepG2 cells with CIK (** $\mathrm{P}<0.01$ vs. $\mathrm{CIK}+$ Inhibitor+NC+HepG2 group). (D) Winn assay and (E) adoptive transfer assay were used to examine the antitumor effect of siPD-1 transfected CIK cells in nude mice. The volume of the tumors in different groups is depicted ( $\mathrm{P}<0.05,{ }^{* *} \mathrm{P}<0.01$ vs. CIK+Inhibitor+NC+HepG2 group). IFN, interferon; siPD-1, small interfering programmed cell death-1; NC, negative control; CIK, cytokine-induced killer; Inhibitor, miR-374b inhibitor; LDH, lactate dehydrogenase; OD, optical density. 


\section{Discussion}

In liver cancer, the activities of liver- and tumor-infiltrating $\mathrm{T}$ cells are restricted due to the presence of multiple immune suppression mechanisms underlying the hepatic microenvironment $(34,35)$. Particularly, the PD-1 signaling pathway negatively regulates antitumor immunity, resulting in lower proliferation, IFN- $\gamma$ production and cytotoxicity by $\mathrm{T}$ cells $(36,37)$. PD-1 is an immune checkpoint inhibitor primarily expressed in CD8+ T lymphocytes, and frequently co-opted via cancer cells to escape immune surveillance (38). Additionally, as a regulator, PD-1 suppresses proliferation and cytokine production of T cells (39). Recently, numerous studies were regarding the functional roles of PD-1 in T lymphocytes (40-42). In addition, previous studies indicated that the anti-PD-1 antibody has the ability to block this checkpoint and induce the regression of several tumor types, including liver cancer, in preclinical studies $(43,44)$. A number of studies revealed the potential role of miRNAs in cancer via affecting the cell proliferation, migration and invasion, through the regulation of different target genes (45-49). Differential expression levels of miRNAs have been indicated to contribute to the initiation and progression of liver cancer $(50,51)$. A previous study reported that miR-4717 suppressed PD-1 expression on lymphocytes in individuals with rs10204525 genotype GG via the interaction with single-nucleotide polymorphisms in the 3'UTR of PD-1 gene, and the suppression of PD-1 expression was associated with increased production of TNF- $\alpha$ and IFN- $\gamma$ (52).

In the present study, it was predicted that miR-374b may target the 3'UTR of PD-1 mRNA. Transfection of CIK cells from individuals with miR-374b mimics significantly suppressed PD-1 mRNA and protein expression in CIK cells. By contrast, the miR-374b inhibitor significantly up regulated the PD-1 expression. In order to investigate the mechanisms underlying the antitumor effects of PD-1 in CIK cells, in vitro and in vivo studies were performed. In vitro, PD-1 high expression CIK cells were obtained through transfecting miR-374b inhibitor into CIK cells. Following this, a siRNA targeting PD-1 was constructed and transfected it to CIK cells to examine the antitumor effects of PD-1. HepG2 cells with high expression of PD-1 were selected as the target cells for the following transfection study. The results demonstrated that IFN- $\gamma$ secretion and the concentration of LDH were significantly increased in the CIK+Inhibitor+siRNA group, compared with the $\mathrm{CIK}+$ Inhibitor+NC group; however, the viability of liver cancer cell line HepG2 in the CIK+Inhibitor+siRNA+HepG2 group had significantly decreased, compared with the HepG2 cells in the CIK+Inhibitor+NC+HepG2 group.

In vivo, Winn assay and adoptive transfer assay were used to examine the antitumor effect of siPD-1 transfected CIK cells in nude mice. The result demonstrated that mice inoculated with HepG2 cells and miR-374b inhibitor transfected CIK cells with PD-1 knocked down had a tumor volume significantly reduced, compared with the control group. The data demonstrated that PD-1is closely associated with the promotion of tumor growth.

These observations support the conclusion that the targeted killing effect of CIK cells was associated with the down regulation of $\mathrm{PD}-1$ gene expression. The novel data provides a deeper understanding of the role of PD-1 in immune regulation and has significant implications for cancer immune therapies targeting PD-1 on CIK cells; therefore, the results in the present study have provided novel target and genetic information, which may be employed for designing new therapeutic modalities against liver cancer. However, further studies are required to validate the interacted role of miR-374b and PD-1 expression and the effect of PD-1 on liver cancer growth in vivo using various liver cancer cell lines. Furthermore, it will be necessary to further explore the functions and mechanisms underlying miR-374b and PD-1 on CIK cells in liver cancer.

\section{Acknowledgements}

The present study was supported by the Key Research and Development Project of Hainan Province from the Hainan Province Science and Technology Department (grant no. ZDYF2016107).

\section{References}

1. El-Serag HB: Epidemiology of viral hepatitis and hepatocellular carcinoma. Gastroenterology 142: 1264-1273.e1261, 2012.

2. Sawyers CL, Abate-Shen C, Anderson KC, Barker A, Baselga J, Berger NA, Foti M, Jemal A, Lawrence TS, Li CI, et al: AACR Cancer progress report 2013. Clin Cancer Res 19: S4-98, 2013.

3. Wang FS, Liu MX, Zhang B, Shi M, Lei ZY, Sun WB, Du QY and Chen JM: Antitumor activities of human autologous cytokine-induced killer (CIK) cells against hepatocellular carcinoma cells in vitro and in vivo. World J Gastroenterol 8: 464-468, 2002.

4. Li XD, Xu B, Wu J, Ji M, Xu BH, Jiang JT and Wu CP: Review of Chinese clinical trials on CIK cell treatment for malignancies. Clin Transl Oncol: 14: 102-108, 2012.

5. Schmidt-Wolf IG, Negrin RS, Kiem HP, Blume KG and Weissman IL: Use of a SCID mouse/human lymphoma model to evaluate cytokine-induced killer cells with potent antitumor cell activity. J Exp Med 174: 139-149, 1991.

6. Chen L: Co-inhibitory molecules of the B7-CD28 family in the control of T-cell immunity. Nat Rev Immunol 4: 336-347, 2004.

7. Freeman GJ, Long AJ, Iwai Y, Bourque K, Chernova T, Nishimura H, Fitz LJ, Malenkovich N, Okazaki T and Byrne MC: Engagement of the PD-1 immunoinhibitory receptor by a novel B7 family member leads to negative regulation of lymphocyte activation. J Exp Med 192: 1027-1034, 2000.

8. Bengsch B, Martin B and Thimme R: Restoration of HBV-specific CD8+ T cell function by PD-1 blockade in inactive carrier patients is linked to T cell differentiation. J Hepatol 61: 1212-1219, 2014.

9. Boni C, Fisicaro P, Valdatta C, Amadei B, Di Vincenzo P, Giuberti T, Laccabue D, Zerbini A, Cavalli A, Missale G, et al: Characterization of hepatitis B virus (HBV)-specific T-cell dysfunction in chronic HBV infection. J Virol 81: 4215-4225, 2007.

10. Fisicaro P, Valdatta C, Massari M, Loggi E, Biasini E, Sacchelli L, Cavallo MC, Silini EM, Andreone P, Missale G and Ferrari C: Antiviral intrahepatic T-cell responses can be restored by blocking programmed death-1 pathway in chronic hepatitis B. Gastroenterology 138: 682-693, 693.e1-4, 2010.

11. Mühlbauer M, Fleck M, Schütz C, Weiss T, Froh M, Blank C, Schölmerich J and Hellerbrand C: PD-L1 is induced in hepatocytes by viral infection and by interferon-alpha and -gamma and mediates T cell apoptosis. J Hepatol 45: 520-528, 2006.

12. Peng G, Li S, Wu W, Tan X, Chen Y and Chen Z: PD-1 upregulation is associated with HBV-specific T cell dysfunction in chronic hepatitis B patients. Mol Immunol 45: 963-970, 2008.

13. Tzeng HT, Tsai HF, Liao HJ, Lin YJ, Chen L, Chen PJ and Hsu PN: PD-1 blockage reverses immune dysfunction and hepatitis B viral persistence in a mouse animal model. PloS One 7: e39179, 2012.

14. Ye P, Weng ZH, Zhang SL, Zhang JA, Zhao L, Dong JH, Jie SH, Pang R and Wei RH: Programmed death-1 expression is associated with the disease status in hepatitis B virus infection. World J Gastroenterol 14: 4551-4557, 2008 
15. Hamid O, Robert C, Daud A, Hodi FS, Hwu WJ, Kefford R, Wolchok JD, Hersey P, Joseph RW, Weber JS, et al: Safety and tumor responses with lambrolizumab (anti-PD-1) in melanoma. N Engl J Med 369: 134-144, 2013.

16. Topalian SL, Hodi FS, Brahmer JR, Gettinger SN, Smith DC, McDermott DF, Powderly JD, Carvajal RD, Sosman JA, Atkins MB, et al: Safety, activity, and immune correlates of anti-PD-1 antibody in cancer. N Engl J Med 366: 2443-2454, 2012

17. Topalian SL, Sznol M, McDermott DF, Kluger HM, Carvajal RD, Sharfman WH, Brahmer JR, Lawrence DP, Atkins MB Powderly JD, et al: Survival, durable tumor remission, and long-term safety in patients with advanced melanoma receiving nivolumab. J Clin Oncol 32: 1020-1030, 2014.

18. Duraiswamy J, Freeman GJ and Coukos G: Therapeutic PD-1 pathway blockade augments with other modalities of immunotherapy $\mathrm{T}$-cell function to prevent immune decline in ovarian cancer. Cancer Res 73: 6900-6912, 2013.

19. Topalian SL, Drake CG and Pardoll DM: Targeting the PD-1/B7-H1(PD-L1) pathway to activate anti-tumor immunity. Curr Opin Immunol 24: 207-212, 2012.

20. Gozuacik D, Akkoc Y, Ozturk DG and Kocak M Autophagy-Regulating microRNAs and Cancer. Front Oncol 7: 65, 2017.

21. Lewis BP, Burge CB and Bartel DP: Conserved seed pairing, often flanked by adenosines, indicates that thousands of human genes are microRNA targets. Cell 120: 15-20, 2005.

22. Jasinski-Bergner S, Mandelboim O and Seliger B: The role of microRNAs in the control of innate immune response in cancer. J Natl Cancer Inst 106: pii: dju257, 2014.

23. Atarod S and Dickinson AM: MicroRNAs: The Missing Link in the Biology of Graft-Versus-Host Disease? Front Immunol 4 $420,2013$.

24. $\mathrm{Xu} \mathrm{XM}$ and Zhang $\mathrm{HJ}$ : miRNAs as new molecular insights into inflammatory bowel disease: Crucial regulators in autoimmunity and inflammation. World J Gastroenterol 22: 2206-2218, 2016.

25. Gong H, Cao Y, Han G, Zhang Y, You Q, Wang Y and Pan Y.: p53/microRNA-374b/AKT1 regulates colorectal cancer cell apoptosis in response to DNA damage. Int J Oncol 50: 1785-1791, 2017.

26. Wu X, Li S, Xu X, Wu S, Chen R, Jiang Q, Li Y and Xu Y: The potential value of miR-1 and miR-374b as biomarkers for colorectal cancer. Int J Clin Exp Pathol 8: 2840-2851, 2015.

27. Hu S, Bao H, Xu X, Zhou X, Qin W, Zeng C and Liu Z: Increased miR-374b promotes cell proliferation and the production of aberrant glycosylated IgA1 in B cells of IgA nephropathy. FEBS Lett 589: 4019-4025, 2015.

28. Liao YY, Tsai HC, Chou PY, Wang SW, Chen HT, Lin YM, Chiang IP, Chang TM, Hsu SK, Chou MC, et al: CCL3 promotes angiogenesis by dysregulation of miR-374b/ VEGF-A axis in human osteosarcoma cells. Oncotarget 7: 4310-4325, 2016.

29. Ma Z, Sun X, Xu D, Xiong Y and Zuo B: MicroRNA, miR-374b, directly targets Myf6 and negatively regulates $\mathrm{C} 2 \mathrm{C} 12$ myoblasts differentiation. Biochem Biophys Res Commun 467: 670-675, 2015.

30. Qian D, Chen K, Deng H, Rao H, Huang H, Liao Y, Sun X, Lu S, Yuan Z, Xie D and Cai Q: MicroRNA-374b suppresses proliferation and promotes apoptosis in T-cell lymphoblastic lymphoma by repressing AKT1 and Wnt-16. Clin Cancer Res 21: 4881-4891, 2015.

31. Schreiber R, Mezencev R, Matyunina LV and McDonald JF: Evidence for the role of microRNA 374b in acquired cisplatin resistance in pancreatic cancer cells. Cancer Gene Ther 23: 241-245, 2016

32. Xie J, Tan ZH, Tang X, Mo MS, Liu YP, Gan RL, Li Y, Zhang L and Li GQ: MiR-374b-5p suppresses RECK expression and promotes gastric cancer cell invasion and metastasis. World J Gastroenterol 20: 17439-17447, 2014.

33. Livak KJ and Schmittgen TD: Analysis of relative gene expression data using real-time quantitative PCR and the 2(-Delta Delta C (T)) method. Methods 25: 402-408, 2001.
34. Crispe IN: Hepatic T cells and liver tolerance. Nat Rev Immunol 3: 51-62, 2003.

35. Protzer U, Maini MK and Knolle PA: Living in the liver: Hepatic infections. Nat Rev Immunol 12: 201-213, 2012.

36. McDermott DF and Atkins MB: PD-1 as a potential target in cancer therapy. Cancer Med 2: 662-673, 2013.

37. Thomson AW and Knolle PA: Antigen-presenting cell function in the tolerogenic liver environment. Nat Rev Immunol 10: 753-766, 2010

38. Odorizzi PM, Pauken KE, Paley MA, Sharpe A and Wherry EJ: Genetic absence of PD-1 promotes accumulation of terminally differentiated exhausted CD8+ T cells. J Exp Med 212: 1125-1137, 2015

39. Spranger S, Koblish HK, Horton B, Scherle PA, Newton R and Gajewski TF: Mechanism of tumor rejection with doublets of CTLA-4, PD-1/PD-L1, or IDO blockade involves restored IL-2 production and proliferation of CD8(+) T cells directly within the tumor microenvironment. J Immunother Cancer 2: 3, 2014.

40. Linedale R, Schmidt C, King BT, Ganko AG, Simpson F, Panizza BJ and Leggatt GR: Elevated frequencies of CD8 T cells expressing PD-1, CTLA-4 and Tim-3 within tumour from perineural squamous cell carcinoma patients. PloS One 12: e0175755, 2017.

41. Liu H, Wang Y, Zeng Q, Zeng YQ, Liang CL, Qiu F, Nie H and Dai Z: Suppression of allograft rejection by CD8+CD122+PD-1+ Tregs is dictated by their Fas ligand-initiated killing of effector $\mathrm{T}$ cells versus Fas-mediated own apoptosis. Oncotarget 8: 24187-24195, 2017.

42. Schmittnaegel M, Rigamonti N, Kadioglu E, Cassará A, Wyser Rmili C, Kiialainen A, Kienast Y, Mueller HJ, Ooi CH, Laoui D and De Palma M: Dual angiopoietin-2 and VEGFA inhibition elicits antitumor immunity that is enhanced by PD-1 checkpoint blockade. Sci Transl Med 9: pii: eaak9670, 2017.

43. Daskivich TJ and Belldegrun A: Words of wisdom. Re: Safety, activity, and immune correlates of anti-PD-1 antibody in cancer. Eur Urol 67: 816-817, 2015

44. Hato T, Goyal L, Greten TF, Duda DG and Zhu AX: Immune checkpoint blockade in hepatocellular carcinoma: current progress and future directions. Hepatology 60: 1776-1782, 2014.

45. Croce CM: Causes and consequences of microRNA dysregulation in cancer. Nat Rev Genet 10: 704-714, 2009.

46. Yongchun Z, Linwei T, Xicai W, Lianhua Y, Guangqiang Z, Ming Y, Guanjian L, Yujie L and Yunchao H: MicroRNA-195 inhibits non-small cell lung cancer cell proliferation, migration and invasion by targeting MYB. Cancer Lett 347: 65-74, 2014.

47. Aleckovic M and Kang Y: Regulation of cancer metastasis by cell-free miRNAs. Biochim Biophys Acta 1855: 24-42, 2015.

48. Di Leva G, Garofalo M and Croce CM: MicroRNAs in cancer. Annu Rev Pathol 9: 287-314, 2014.

49. Zhang Y, Yang P and Wang XF: Microenvironmental regulation of cancer metastasis by miRNAs. Trends Cell Biol 24: 153-160, 2014.

50. Mao B and Wang G: MicroRNAs involved with hepatocellular carcinoma (Review). Oncol Rep 34: 2811-2820, 2015.

51. Giordano S and Columbano A: MicroRNAs: New tools for diagnosis, prognosis, and therapy in hepatocellular carcinoma? Hepatology 57: 840-847, 2013.

52. Zhang G, Li N, Li Z, Zhu Q, Li F, Yang C, Han Q, Lv Y, Zhou Z and Liu Z: microRNA-4717 differentially interacts with its polymorphic target in the PD1 3' untranslated region: A mechanism for regulating PD-1 expression and function in HBV-associated liver diseases. Oncotarget 6: 18933-18944, 2015.

This work is licensed under a Creative Commons

Attribution-NonCommercial-NoDerivatives 4.0 International (CC BY-NC-ND 4.0) License. 